\title{
RESEARCH AND PRACTICE OF UAV REMOTE SENSING IN THE MONITORING AND MANAGEMENT OF CONSTRUCTION PROJECTS IN RIPARIAN AREAS
}

\author{
Jingmin $\mathrm{Yu}^{1 *}$, Zheng Gan ${ }^{1}$, Liang Zhong ${ }^{1}$, Lijuan Deng ${ }^{1}$ \\ ${ }^{1}$ Changjiang Spatial Information Technology Engineering Co., Ltd, Wuhan, China- yjingmin@ 126.com
}

Commission III, WG III/7

KEY WORDS: UAV remote sensing, monitoring and management, riparian area, construction projects, reservoir

\begin{abstract}
:
The objective of this paper is to investigate the use of UAV remote sensing in the monitoring and management of construction projects in riparian areas through the case study of embankment construction projects' monitoring in the Three Gorges Reservoir area. A three-step approach is proposed to address the problem: data acquisition with UAV, data processing, and monitoring information extraction. The results of the case study demonstrate that UAV remote sensing is capable of providing fast and accurate measurements and calculations for the needs of monitoring of riparian constructions.
\end{abstract}

\section{INTRODUCTION}

Occurring at land-water junction alongside natural waterways, riparian areas play a unique and significant role in ecology, environmental management, and civil engineering because of their role in soil conservation, species diversity promoting, the influence they have on fauna and aquatic ecosystems and so on (Groffman et al, 2003).

For the social-economic development in the watershed area, there are a number of construction projects approved of by the government in certain riparian areas, including embankment construction projects, tourist attractions and large-scale distribution centers. The embankments will reduce water and soil erosion, prohibit mud and sand from flowing into the water, and most importantly, protect the inhabitants from the threat of floods. The tourist attractions and distribution centers will become new drive for the growth of local economy. Though bringing about economic and social benefits, these construction projects inevitably cause disturbance to the ecosystems of the riparian area.

There is a great need to monitor the construction projects along the riverside by obtaining information about the current state of projects (Yang, 2014). On one hand, the policy-makers rely on that information to keep a close eye on the construction site to make sure no extra harm is being done to the local environment. On the other hand, the construction manager need to assure the construction is progressing as scheduled. Gaining up-to-date information of construction sites consists of continuous surveying the constantly changing shape of the site and its elements such as location, extent, and reliable computation of cut and fill volume etc (Zhao, 2016; Simeoni, 2014). The conventional field surveying can hardly meet the requirements of this task because it's time consuming, while in this case the policy-makers and construction managers need to be presented with the fastest, most effective and reliable data of construction sites.

Though motivated primarily by military goals, UAV technology has seen extensive use in a wide range of applications, including agriculture, forestry (Kubota et al, 2017), archaeology and architecture, emergency service and traffic monitoring (Nex and Remondino, 2014). What makes UAV so favourable is mainly due to its fast and accurate data acquisition ability comparing with conventional methods. This ability has been strengthened by the rapid development of the navigation and orientation payload and the remote-sensing payload, i.e., GNSS/INS systems and amateur or SRL digital cameras, allowing for high mapping accuracy in geometric applications (Carvajal et al, 2011). These facts make UAV remote sensing a possible solution for the aforementioned monitoring problem.

This paper tends to explore the feasibility of applying UAV remote sensing for the monitoring and management of construction projects in riparian areas. To address this problem, a three-step methodology is proposed: data acquisition with UAV, data processing, and monitoring information extraction. And the practicability of this methodology is validated through the case study of the construction project' monitoring in the Three Gorges Reservoir (TGR) area.

\section{DATA ACQUISITION WITH UAV}

A typical image-based field surveying with UAV systems requires a flight or mission planning, image acquisition and GCPs survey.

\subsection{UAV platform}

Nowadays the market provides with numerous UAV platforms with different specifications and for different applications. The primary UAV airframe types are fixed and rotary wings. The fixed-wing platforms have the advantages of longer flight durations at higher speeds, but they are dependent on either a launcher or a runway to facilitate takeoff and landing. On the other side, the rotary-wing UAVs are able to takeoff and land vertically, and to hover and perform agile manoeuvring, with shorter fight duration (Tang and Shao, 2015). In our case, the study area is relatively small, and is located in the mountainous TGR area. Therefore, the rotary-wing type is more suitable. The Phantom 4 Pro is chosen as the UAV platform. It is equipped with 12 MP CMOS Sony camera and the image resolution is 
$5472 * 3648$ pixels. It can fly up to 30 minutes in pre-planned flight path with GPS/GLONASS satellite support.

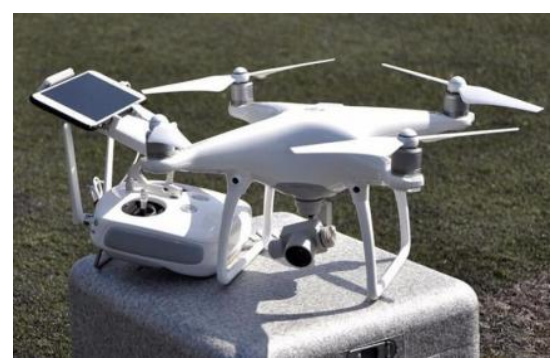

Figure 1. UAV platform

\subsection{Location of the study area}

An embankment construction project by the riverside of Xiangxi River, a tributary of Yangtze River upstream is selected as our case study. Along the riparian areas of TGR area there are a set of low-lying embankment constructions following up the Three Gorges Dam (TGD) project. The local government needs to monitor these constructions, especially to make sure that they haven't occupied the TGR'S designed flood storage space without permission, because the TGR's capability to prevent flooding downstream is realized by providing flood storage space in the reservoir area ( $\mathrm{Li}$ et al, 2010). The topography there is characterized by a mountainous landscape.

Located in Zhaojunzhen, a town in the city of Xingshan, the embankment construction winds along the river bank for 520 meters. The project consists of two parts, the embankment and the backfill, and the embankment is designed to begin at the height of $165 \mathrm{~m}$ and end at $176 \mathrm{~m}$. The construction began in May of 2014 and was completed in July 2016.
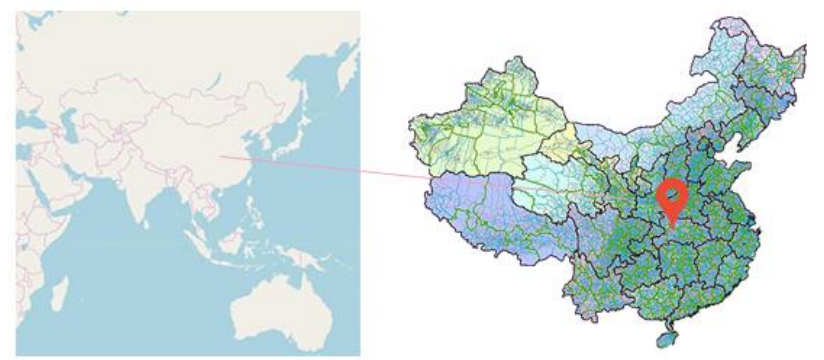

Figure 2. Location of study area

\subsection{UAV flight}

The maximum height difference of the study area is about 100 meters. The flight route design is set with $6 \mathrm{~cm} /$ pixel ground resolution, $80 \%$ longitudinal overlap and $60 \%$ lateral overlap, and an average flying height of $200 \mathrm{~m}$ above the ground.

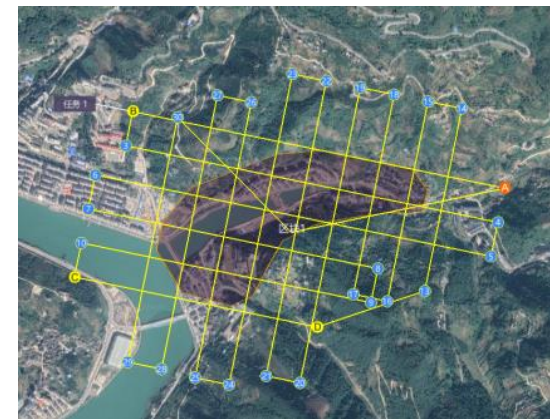

Figure 3. UAV flight plan

\subsection{Control survey}

Reliable ground control points(GCPs) are crucial for the georeferencing and orientation of aerial images. Considering the fact that the GPS service onboard the Phantom 4 Pro is consumer grade, GCP survey is indispensable in our study.

Ground control points(GCPs) are established around the extent of the area of interest prior to the flight, and they are arranged according to the relevant specification requirements. There are nine GCPs (in the surrounding and in the middle) set in the site, as shown in Figure 4. Each GCP is created by painting white crosses with about one-meter width on the ground. Coordinates of the GCPs are measured by GPS receiver working with RTK mode using Continuously Operating Reference Station (CORS).

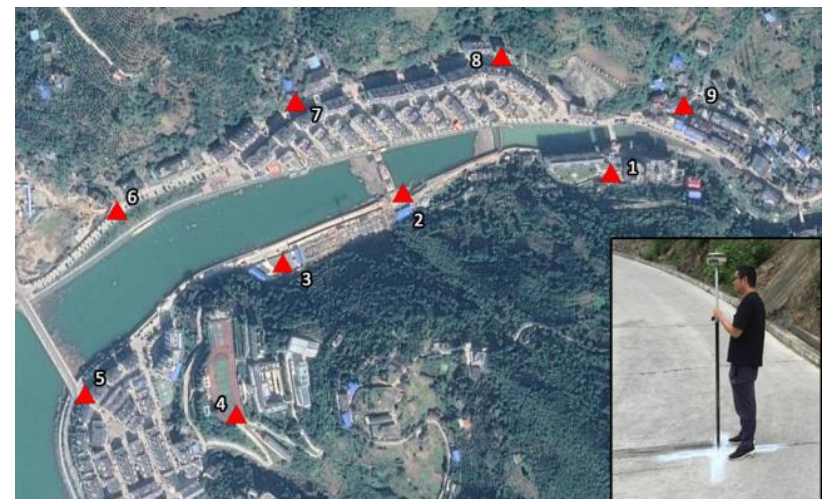

Figure 4. GCP locations in relation to the study area

\section{DATA PROCESSING}

The designed flight results in 413 aerial images, and such data is processed with Contextcapture center, which offers automatic aerial triangulation, point cloud generation and DSM generation.

\subsection{Aerial Triangulation}

Aerial triangulation is the process to determine the ground coordinate and orientation of an aerial image. During Aerial triangulation process, the GCPs are added to makes it possible to accurately georeference images and to avoid long-range metric distortion. Seven GCPs in the surroundings are selected as control points and the remaining ones are used as checkpoints. Table 1 gives the accuracy of GCPs from aerial triangulation. 


\begin{tabular}{|l|c|c|}
\hline GCP No. & $\begin{array}{c}\text { RMS of horizontal } \\
\text { errors[m] }\end{array}$ & $\begin{array}{c}\text { RMS of vertical } \\
\text { errors[m] }\end{array}$ \\
\hline GCP1 & 0.001 & 0.000 \\
GCP3 & 0.001 & 0.000 \\
GCP4 & 0.001 & -0.001 \\
GCP5 & 0.002 & 0.001 \\
GCP6 & 0.002 & 0.000 \\
GCP8 & 0.001 & -0.002 \\
GCP9 & 0.002 & 0.001 \\
RMS Error & 0.002 & 0.001 \\
\hline
\end{tabular}

Table 1. Residual of ground control points

\subsection{Point cloud generation and 3D model building}

Point cloud densification is the next step, and points are automatically triangulated in order to produce the mesh type model of the mapped surface. Further on, a 3D textured mesh of the surface is generated, as shown in Figure 5. After all of that, the DSM and orthomosaic of the study area are produced as in Figure 6 and Figure 7. The overall time for this photogrammetric process is about 5 hours.

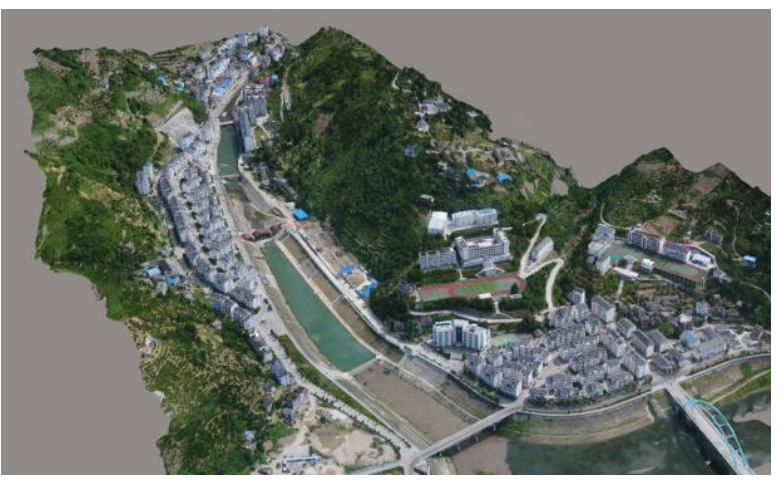

Figure 5. 3D textured mesh surface of the study area

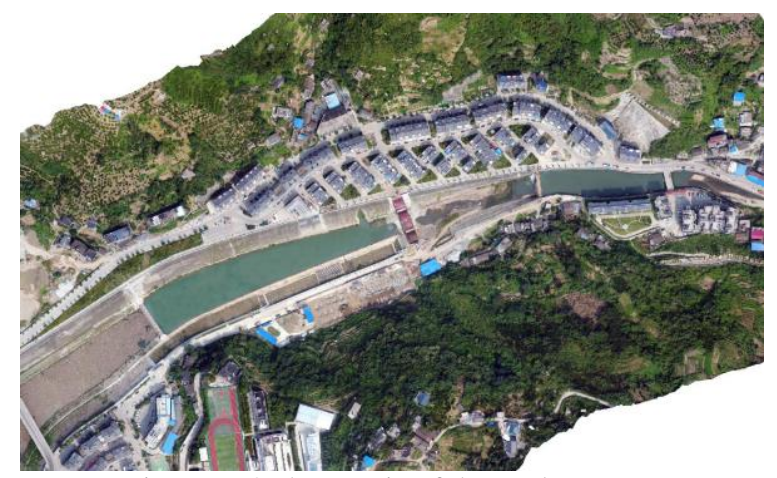

Figure 6. Orthomosaic of the study area

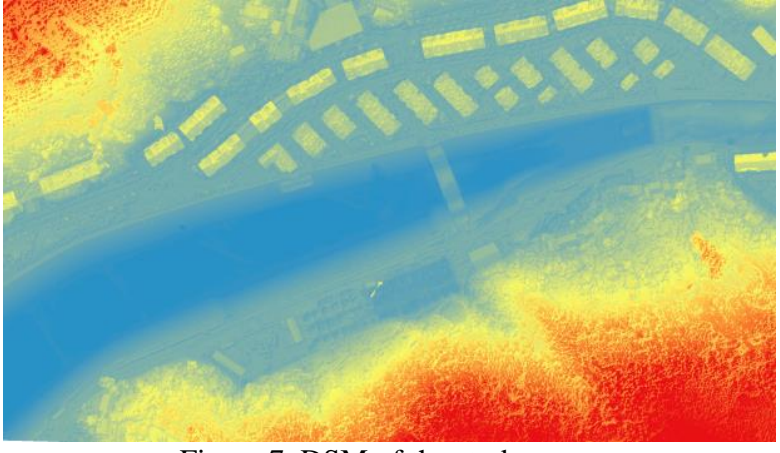

Figure 7. DSM of the study area

\subsection{Accuracy of the photogrammetric model}

Two GCP points in the middle, GCP 2 and GCP 7, are left as check points. The accuracy of check points indicates the accuracy of model, as shown in Table 2.

\begin{tabular}{|l|c|c|}
\hline GCP No. & $\begin{array}{c}\text { RMS of horizontal } \\
\text { errors[m] }\end{array}$ & $\begin{array}{c}\text { RMS of vertical } \\
\text { errors[m] }\end{array}$ \\
\hline GCP2 & 0.094 & 0.303 \\
GCP7 & 0.11 & 0.295 \\
RMS Error & 0.102 & 0.299 \\
\hline
\end{tabular}

Table 2. Residual of check points

\section{MONITORING INFORMATION EXTRACTION}

According to the different types of monitoring objects and monitoring purposes, the information to be extracted varies. The methods to extract monitoring information can be categorized into the following three groups:

\section{a. Manual delineation}

To delineate precisely the spatial extent of the construction site based on DOM with high resolution, in order to acquire the location and area of the construction site.

\section{b. Visual observation}

To get the existing conditions of the construction project and other onsite information through observing 3D model or DOM.

\section{c. Calculation based on DSM}

By comparing the DSM of two periods, the cut and fill volume can be calculated. Besides, the slope of construction site can also be acquired when slope monitoring is needed.

In our study case, what concerns the managing department is the location, extent/area, the status of the construction site, and most important of all, the TGR's flood storage volume occupied by this embankment construction.

By overlaying the as-built drawing of construction extent (as shown by red line in Figure 8 and Figure 9) on the orthomosaic from UAV data and archived DOM of this area in 2013, the terrain changes caused by the construction can be detected. This construction consists of two parts, the embankment and backfill. The total disturbed area is measured to be $38,100 \mathrm{~m}^{2}$. 


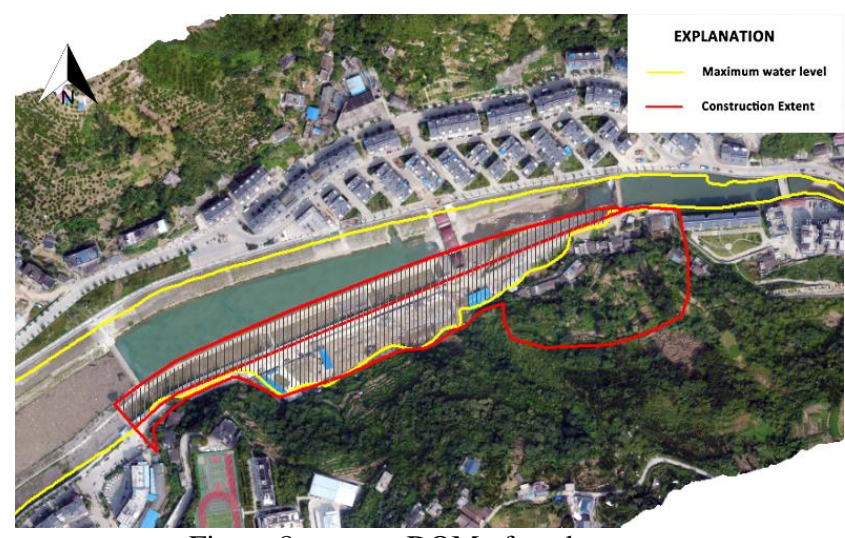

Figure 8. current DOM of study area

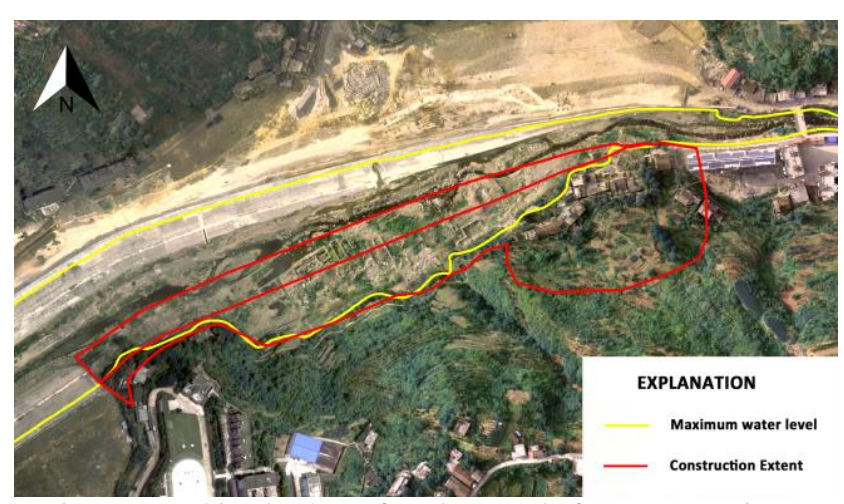

Figure 9. archived DOM of study area (before construction)

To calculate TGR's flood storage volume occupied by this construction, we overlay contour line with the height of $175 \mathrm{~m}$ (maximum elevation of designed flood storage volume), as shown with yellow line in Figure 8 and Figure 9. The TGR's flood storage volume occupied by this embankment construction is just the cut and fill volume below $175 \mathrm{~m}$, which is the shaded part in Figure 8. Buildings and vegetation were filtered from DSM to produce the DEM of the shaded extent, and the final DEM is given in FIG 10.

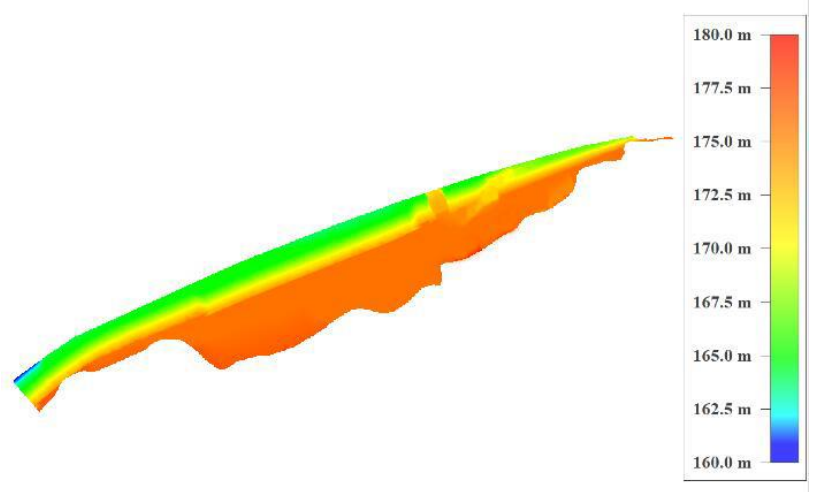

Figure 10. current DEM (2017)

By comparing the current DEM and the archived DEM (2013) before the construction (shown in Figure 11), the terrain changes can be calculated (Figure 12). Based on this data, the TGR's flood storage volume occupied by this embankment construction is $141,866 \mathrm{~m}^{3}$.

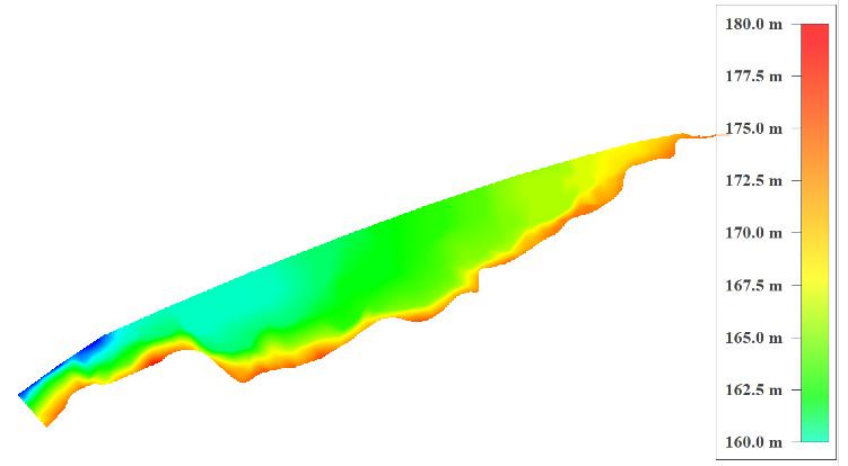

Figure 11. archived DEM (2013)

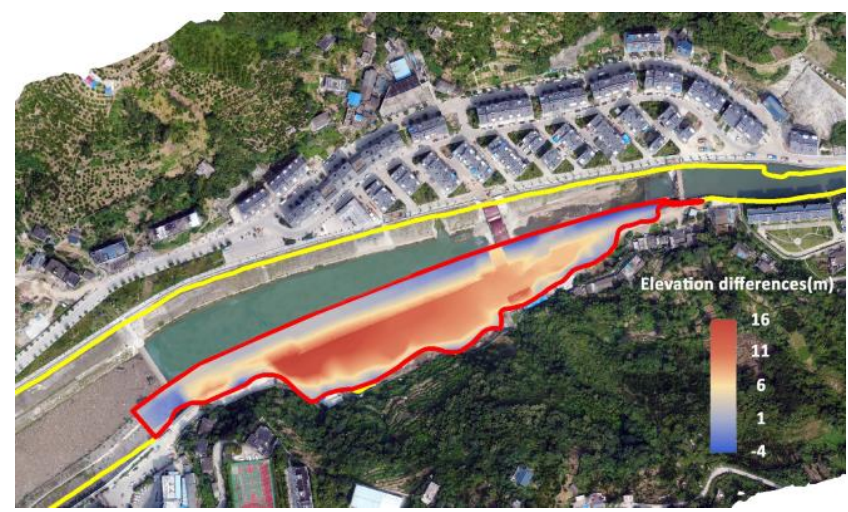

Figure 12. Increase in elevation of by comparison of archived DEM and the current DEM

\section{CONCLUSION}

This paper proposed the methodology of monitoring riparian construction projects using UAV remote sensing. And validated this method by applying it in the case study on the embankment construction by the riverside of Yangtze river.

It's noteworthy that the UAV-based method greatly improves the efficiency of monitoring work by shortening half of the time needed with conventional method. The overall time it takes is about two days (with one day in field surveying and one day in data processing and monitoring information extraction). While using conventional terrain survey, the field work alone will take at least three days to complete and two more days to produce DEM and DOM.

Further, with UAV data acquired in different time, dynamic monitoring with high-resolution can be performed. Given the flexibility of UAV, the time interval can be adjusted to whenever needed. This makes UAV can be applied not only in the usual repeated monitoring, but also in the disaster response in riparian managing, supporting the decision-making in emergency with increased precision and reduced cost.

\section{REFERENCES}

Carvajal F., Agüera F., Pérez M., 2011. Surveying a landslide in a road embankment using unmanned aerial vehicle photogrammetry. International Conference on Unmanned Aerial Vehicle in Geomatics. 2011, pp. 14-16. 
The International Archives of the Photogrammetry, Remote Sensing and Spatial Information Sciences, Volume XLII-3, 2018 ISPRS TC III Mid-term Symposium "Developments, Technologies and Applications in Remote Sensing", 7-10 May, Beijing, China

Groffman, P. M., et al., 2003. Down by the riverside: urban riparian ecology. Frontiers in Ecology and the Environment, 1(6), pp. 315-321.

Kubota S., Kawai Y., Kadotani R., 2017. Accuracy Validation of Point Clouds of UAV Photogrammetry and its Application for River Management. ISPRS-International Archives of the Photogrammetry, Remote Sensing and Spatial Information Sciences, 2017, pp. 195-199.

Li X., et al., 2010. Dynamic control of flood limited water level for reservoir operation by considering inflow uncertainty. Journal of hydrology, 391(1), pp. 124-132.

Nex, F. and Remondino, F., 2014. UAV for 3d mapping applications: a review. Applied Geomatics, 6(1), pp. 1-15.

Simeoni L., Zatelli P., Floretta C., 2014. Field measurements in river embankments: validation and management with spatial database and webgis. Natural Hazards, 71(3), pp. 1453-1473.

Tang, L. and Shao, G., 2015. Drone remote sensing for forestry research and practices. Journal of Forestry Research, 26(4), pp. 791-797.

Yang, S., 2014. Practice and thinking of construction project management within Yangtze River management scope. Water Conservancy Construction and Management, 34(6), pp. 48-50.

Zhao, H. B., 2016. Legislations on examination standards for river-related project construction. China Water Resources, 2016(18), pp. 36-39. 